\title{
Tourist relative importance of factors influencing tourism development in J\&K
}

\author{
Asif Iqbal Fazili', Shahid Ali ${ }^{2}$,", Danish Khan ${ }^{3}$ \\ ${ }^{1}$ Senior Assistant Professor, ${ }^{2}$ Research Scholar, Dept. of Management Studies, Islamic University of Science and Technology, \\ Awantipora, Jammu \& Kashmir, ${ }^{3}$ Assistant Professor, Dept. of Management Studies, University of Kashmir, Srinagar, Jammu \& \\ Kashmir, India
}

*Corresponding Author:

Email: dihah7692@yahoo.com

\begin{abstract}
National tourism policy of 2002 has identified seven key factors which plays a vital role in tourism development. Few researchers have confirmed the underlying factor structure of 7 key factors in determining the tourism development. Still this literature demands the support of results of relative importance in finding the contribution a particular factor makes in combination with other factors. So, the present study is an extension to the existing literature. An empirical study has been conducting in order to find out the perception of the tourists visiting Jammu \& Kashmir by examining the relative importance of 7 key factors influencing the tourism development. The paper also highlights the key statements responsible for the tourism development and suggests measures to prioritize the influencing factors accordingly.
\end{abstract}

Keywords: National tourism policy, Seven key factors, Relative importance, Index.

\section{Introduction}

'Tourism is a goose that not only lays a golden egg, but also fouls its own nest'

(Hawkins, 1982)

The World Tourism Organization (WTO) defined Tourism as "tourism comprises the activities of persons traveling to and staying in places outside their usual environment for not more than one consecutive year for leisure, business and other purposes". (WTO, 1995)

In India, the tourism both local and international has increased multifold where numbers are increasing every year. The annual growth rate has barged to $4.5 \%$ with number of Foreign Tourist Arrivals (FTAs) stood at 8.03 million in the year 2015. India is positioned at 40th in World Tourist Arrivals with its share in international tourist arrivals at $0.68 \%$. The 12 th five year plan (2012-2017) has considered tourism sector as major component in service industry with predictions of growth for tourism to rose up to $12 \%$ p.a. (India Tourism Statistics, 2015).

In order to compete and excel in tourism, the Govt. of India has come with many initiates like framing for the first time, policy on tourism in the year 1982. This was the first national tourism policy to set tourism in the country on a new path. The policy statement emphasized on fostering international tourism and increased attention to regional tourism. A new initiative was proposed to develop cultural tourism, pilgrimage tourism and preserving ancient monuments \& arts. To achieve set objectives, it stressed on exploring markets of west Asia and North African countries. A due recognition was laid on better private-public partnerships for achieving aims of the policy. The second tourism policy, also called national tourism policy came up in 2002 with many new initiates for fostering the growth of local and international tourism. For the first time, it has been successful in the international arena to position India as a unique brand with its campaign of incredible India. The policy has set many targets and objectives for the nation to achieve with focus on seven key factors. It provided in a systematic manner a strategic intent for the growth of tourism in the country. The policy focused on both local and international tourists as means to harness growth, employment generation and impetus to rural tourism. The policy identified seven key factors that will provide the thrust to tourism development as (a) Swagat (welcome) (b) Soochna (information) (c) Suvidha (facilitation) (d) Suraksha (safety) (e) Sahyog (cooperation) (f) Samrachana (infrastructure) (g) Safai (cleanliness). In order to achieve aims of the policy, these seven key factors were considered as benchmark to compete at global level and uncap vast potential of India as a destination. The purpose of the government is to ensure that every tourist visiting the country is 'physically invigorated, mentally rejuvenated, culturally enriched and spiritually elevated'. The seven key factors are main benchmarks for each state to excel in continuously for development of tourism in that area.

\section{Literature Review}

Tourism affects the economy and the lives of societies and has proven to be a lifesaver for many destinations. There are real and perceived fears that are sometimes attributed to tourism and largely related to poorly managed or mass tourism ventures. As with any economic activity, tourism can have negative impacts on communities. These must be minimized and measured against the benefits that tourism brings. (Lee et al., 2010)

Tourism can be a positive input, for the development of physical, social, cultural, economic and environmental aspects of a country. (Gunce, 2003) 
According to Smith (1995), tourism can play an important contribution to poverty alleviation, employment, generation and the development of remote areas.

Tourism developments have both costs and benefits (Prentice, 1993).

Tourism and its policy have received paramount importance due to theoretical as well as practical significance. The practical significance has increased manifold owing to global cooperation in international travel including bilateral airline negotiations, increased endowments of facilities and services, fast exchanges with other sectors, more use of public maintained resources (like national parks) as attractions, easy allotting of visas for tourists and in financing of marketing for particular destinations. (Ahmed \& Krohn, 1990)

Before 1956, tourism in India was related to visiting relatives/friends \& pilgrimage. It was not until year 1966, India Tourism Development Corporation (ITDC) was setup involving India as holiday destination as well. In India, before tourism policy of 1982, states like Kerala, Jammu and Kashmir, Goa and Himachal Pradesh had somehow tourism part of state's five year plans. In 1980, for the first time, an important policy initiative got taken with hosting of Asian Games which led GOI to plan for handling visitors attracted by the event. In the year 1982, the heightened public interest took shape of a well thought out action plan as tourism policy providing to handle tourist arrivals through tourism circuits. (Singh, 2001)

Tourism policy of 1982 , in order to handle the tourists, came up with concept of tourist circuits consisting of geographically linked tourist sites like Delhi-Jaipur-Agra and the Bombay-Goa shopping-andbeach circuit. These circuits were grossly oversold resulting in the concept of alternative circuits to lure the tourists. The alternative circuits were thought imperative to divert rush from overcrowded circuits. (Gantzer \& Gantzer, 1983)

The policy of 1982 gave a six point plan for growth of tourism (a) Swagat (welcome) (b) Soochna (information) (c) Suvidha (facilitation) (d) Suraksha (safety) (e) Sahyog (cooperation) (f) Samrachana (infrastructure) (g) Safai (cleanliness). The main aim of this policy was to promote balanced socio-economic development, promote and preserve the rich heritage and culture of India and also create employment opportunities.

An empirical study on seven key factors of 2002 National tourism policy resulted in the 22 item measurement scale for tourism development (Khan and Kirmani, 2018). The seven factors along with the 22 items were used in the present study to extend the scope of the relative importance of factors influencing the tourism development.

In 1997, the tourism department came up with a new National tourism action plan owing to growing public interest in tourism. Heightened public interest was mainly due to two reasons (a) tourism as export industry (b) tourism finance corporation attracting private investors. The plan maintained the aforesaid tourist circuits with initiates to better marketing, infrastructure and human resource to develop tourism in the country. The plan for some was nothing drastically new rather put in more fashionable lexicon (Singh, 2001). Others were of the view that plan was overambitious \& unrealistic. The funds spared for implementing the plan were not properly matched to challenges of quantitative targets (Raguraman, 1998).

The action plan of 1997 was translated into tourism policy 2002 designed by Govt. in the Centre. The policy aimed at developing local and international tourism. The policy to a large extent, concerns old wine in new bottles as it sets exemplary goals for the development of tourism in the country. To start with, the policy document attempts to establish tourism's great contribution to national development and its role as an engine of growth. It suggests that tourism not only generates government revenue, foreign currency, but also provides an optimal use of India's scarce resources, sustainable development, high quality employment (especially to youngsters, women and disabled people), and finally, peace, understanding, national unity and stability (GOI, 2002).

There is lack of coordination between the various players involved. This has resulted in poor infrastructure facilities, lack of health care facilities and a sense of insecurity for the tourists. There is a need for a framework to be evolved which is government led, private sector driven and community welfare oriented (Fazili and Ashraf, 2006).

\section{Objectives}

1. To study the factors responsible for the development of tourism in J\&K.

2. To analyze the factors on the basis of RII in order to give an understanding to the extent each factor contribute to the development of tourism in J\&K.

\section{Research Methodology}

On the basis of time dimension, it is a Crosssectional study as it was carried out once and represents a snapshot of one point in time. The various tourist destinations of $J \& K$ state are visiting by local and foreign tourists. This paper focuses on the perception perspective of local and foreign tourists as well. Hair et al $(1998,2010)$ suggested 5 or 10 cases or respondents per question. This study uses 110 samples ( 5 cases per question, $\left.5^{*} 22=110\right)$. The data is collected by distributing the questionnaire among the 110 tourists. After sorting the questionnaires, only 96 questionnaires are valid with a good respondent rate of $87.27 \%$.

Primary data was primarily used for the study. In order to find out the demographic characteristics, descriptive statistics was conducted on the demographic 
variables. Also, in order to empirically determine the factors accounting for tourism development and to give an understanding as to the extent to which each factor contribute to tourism development, the Relative Importance Index (RII) was employed. Relative Importance Index or weight is a type of relative importance analyses. RII was used for the analysis because it best fits the purpose of this study. Johnson (2000) defines relative weight (also called relative importance) as the proportionate contribution each predictor makes to $\mathrm{R} 2$, considering both its unique contribution and its contribution when combined with other variables. According to Johnson and LeBreton (2004), RII supports in finding the contribution a particular variable makes to the prediction of a criterion variable both by itself and in combination with other predictor variables. Further, supported by Tonidandel et al. (2009) that relative weights allow one to make statements regarding the contribution of variables relative to other variables in the model.

For calculation of the Relative Importance Index (RII), the formula below was used (Badu et al., 2013; Ali and Fazili, 2017): $\quad$ RII $=\Sigma W /(A * N)$
Where, W-weightage given to each statement by the respondents and ranges from 1 to 5; A-Higher response integer (5); and $\mathrm{N}$-total number of respondents.

Further, secondary data is used to create a theoretical background of the Study and to analyze the data in context of tourism development through previously available information in the form of articles, journals, editorials, research papers and books.

\section{Research Findings}

In order to find out the demographic features, descriptive statistics was conducted on the demographic variables. The demographic features depict that male respondents (71 percent) are more as compared to female respondents $(29$ percent $)$. Most of the respondents are of age 31-40 accounting to 48 percent. As matter of fact, majority of the respondents accounting to 68 percent are domestic tourists and the foreign tourists accounted for 32 percent only. The findings are shown in Table 1.

Table 1: Demographic profile of respondents (96)

\begin{tabular}{|c|c|c|c|}
\hline Items & Percentage & Items & Percentage \\
\hline \multicolumn{2}{|l|}{ Age } & \multicolumn{2}{|c|}{ Tourist Type } \\
\hline Upto 20 & 8 & Domestic & 68 \\
\hline $21-30$ & 26 & Foreign & 32 \\
\hline $31-40$ & 48 & Gender & \\
\hline Above 40 & 18 & Male & 71 \\
\hline & & Female & 29 \\
\hline
\end{tabular}

Source: Authors

For a Likert five-point response item, Relative Importance Index (RII) produces a value ranging from 0.2 - 1.0 (Badu et al., 2013). Therefore, the group index is the average of the Relative Importance Index for the variables in the various groups (Fugar \& Agyakwah,
2010). The values $0.751,0.688,0.699,0.791,0.769$, 0.697 and 0.703 indicate respectively the RII values of Welcome (Swagat), Information (Soochna), Facilitation (Suvidha), Safety (Suraksha), Cooperation (Sahyog), Infrastructure (Samrachna) and Cleanliness (Safai), as shown in Table 2.

Table 2: Factors influencing the tourism development of J\&K state

\begin{tabular}{|c|c|c|c|c|c|c|c|c|}
\hline Factors & 1 & 2 & 3 & 4 & 5 & $\mathbf{W}$ & RII & Rank \\
\hline Welcome (Swagat) & & & & & & & 0.751 & 3 \\
\hline People in $J \& K$ are friendly & 0 & 5 & 19 & 28 & 44 & 399 & 0.831 & \\
\hline Transporters in Kashmir are hospitable & 2 & 14 & 30 & 32 & 18 & 338 & 0.704 & \\
\hline Shopkeepers are lively \& interactive & 3 & 8 & 30 & 40 & 15 & 344 & 0.717 & \\
\hline Information (Soochna) & & & & & & & 0.688 & 7 \\
\hline $\begin{array}{l}\text { Required information about the accommodation at different } \\
\text { places in J\&K is easily available }\end{array}$ & 2 & 14 & 34 & 37 & 9 & 325 & 0.677 & \\
\hline $\begin{array}{l}\text { Required information about the transportation costs to } \\
\text { different destination is openly available }\end{array}$ & 2 & 14 & 30 & 38 & 12 & 332 & 0.692 & \\
\hline $\begin{array}{l}\text { Required information about safety measures at tourist } \\
\text { destinations is provided by concerning authorities }\end{array}$ & 3 & 13 & 25 & 45 & 10 & 334 & 0.696 & \\
\hline Facilitation (Suvidha) & & & & & & & 0.699 & 5 \\
\hline $\begin{array}{l}\text { Accommodation is easily available at most of the tourist } \\
\text { destinations in J\&K }\end{array}$ & 3 & 11 & 24 & 44 & 14 & 343 & 0.715 & \\
\hline Transporters are available round the clock in J\&K & 8 & 16 & 22 & 37 & 13 & 319 & 0.665 & \\
\hline
\end{tabular}




\begin{tabular}{|c|c|c|c|c|c|c|c|c|}
\hline $\begin{array}{l}\text { Quality food is available at most of the tourist destinations in } \\
\text { J\&K }\end{array}$ & 1 & 14 & 30 & 30 & 21 & 344 & 0.717 & \\
\hline Safety (Suraksha) & & & & & & & 0.791 & 1 \\
\hline I feel safe and secure in $J \& K$ & 2 & 8 & 21 & 29 & 36 & 377 & 0.785 & \\
\hline It is easier for women tourist tourists to roam freely in $J \& K$ & 0 & 9 & 22 & 33 & 32 & 376 & 0.783 & \\
\hline I will recommend others to visit $J \& K$ because I feel safe here & 1 & 11 & 14 & 29 & 41 & 386 & 0.804 & \\
\hline Cooperation (Sahyog) & & & & & & & 0.769 & 2 \\
\hline People in J\&K are very helpful & 2 & 5 & 13 & 35 & 41 & 396 & 0.825 & \\
\hline $\begin{array}{l}\text { Transporters properly assist in reaching different destinations } \\
\text { of } \mathrm{J} \& \mathrm{~K}\end{array}$ & 0 & 11 & 20 & 40 & 25 & 367 & 0.765 & \\
\hline $\begin{array}{l}\text { One finds ample assistance available for tourists in hours of } \\
\text { need }\end{array}$ & 1 & 11 & 29 & 41 & 14 & 344 & 0.717 & \\
\hline Infrastructure (Samrachna) & & & & & & & 0.697 & 6 \\
\hline $\begin{array}{l}\text { J\&K has a large number of food outlets which provide quality } \\
\text { service }\end{array}$ & 1 & 9 & 22 & 41 & 23 & 364 & 0.758 & \\
\hline $\mathrm{J} \& \mathrm{~K}$ fulfills accommodation needs of all classes of tourists & 4 & 10 & 24 & 38 & 20 & 348 & 0.725 & \\
\hline $\begin{array}{lll}\text { J\&K has excellent communication services(internet \& } \\
\text { telecom) available round the clock }\end{array}$ & 7 & 18 & 32 & 28 & 11 & 306 & 0.638 & \\
\hline J\&K has good Road network & 3 & 14 & 35 & 36 & 8 & 320 & 0.667 & \\
\hline Cleanliness (Safai) & & & & & & & 0.703 & 4 \\
\hline Most of the hotels I have visited were clean & 2 & 6 & 32 & 41 & 15 & 349 & 0.727 & \\
\hline $\mathrm{J} \& \mathrm{~K}$ roads are clean & 7 & 13 & 24 & 35 & 17 & 330 & 0.688 & \\
\hline Most of the restaurants I have visited have clean space & 4 & 15 & 27 & 31 & 19 & 334 & 0.696 & \\
\hline Source: Authors & & & & & & & & \\
\hline
\end{tabular}

Likewise, the RII values indicate that, primarily, Welcome (Swagat), Information (Soochna), Facilitation (Suvidha), Safety (Suraksha), Cooperation (Sahyog), Infrastructure (Samrachna) and Cleanliness (Safai) factors influence tourism development. Similarly, it suggests that, Safety (Suraksha) ranked the first significantly influential factor that accounts for tourism development. This was sequentially followed by Cooperation (Sahyog) factor, Welcome (Swagat), Cleanliness (Safai), Facilitation (Suvidha), Infrastructure (Samrachna) and Information (Soochna) factors.

Safety (Suraksha): The Safety (Suraksha) factor grouping variable (0.791) was ranked the first significantly influential factor that accounts for tourism development by the respondents. Individually, recommend others to visit $J \& K$ because it is safe (0.804) and feel safe and secure in J\&K (0.785) was ranked the highest variable under Safety (Suraksha) factor indicating more important to tourism development than the other variables. On the other hand, Easier for women tourists to roam freely in $\mathrm{J} \& \mathrm{~K}$ (0.783) was ranked low, thus there is the need to intensify and strictly focus on these respective factors.

Cooperation (Sahyog): The Cooperation (Sahyog) factor grouping variable (0.769) was ranked the second significantly influential factor that accounts for tourism development by the respondents. Individually, people in J\&K are very helpful (0.825) and Transporters properly assist in reaching different destinations of $J \& K(0.765)$ was ranked the highest variable under Cooperation (Sahyog) factor indicating more important to tourism development than the other variables. On the other hand, ample assistance available for tourists in hours of need (0.717) was ranked low, thus there is the need to intensify and strictly focus on these respective factors.

Welcome (Swagat): The Welcome (Swagat) factor grouping variable $(0.751)$ was ranked the third significantly influential factor that accounts for tourism development by the respondents. Individually, people in $\mathrm{J} \& \mathrm{~K}$ are friendly (0.831) and shopkeepers are lively \& interactive (0.717) was ranked the highest variable under Welcome (Swagat) factor indicating more important to tourism development than the other variables. On the other hand, transporters in Kashmir are hospitable (0.704) was ranked low, thus there is the need to intensify and strictly focus on these respective factors.

Cleanliness (Safai): The Cleanliness (Safai) factor grouping variable $(0.703)$ was ranked the fourth significantly influential factor that accounts for tourism development by the respondents. Individually, most of the hotels visited are clean (0.727) and most of the restaurants visited have clean space (0.696) was ranked the highest variable under Cleanliness (Safai) factor indicating more important to tourism development than the other variables. On the other hand, J\&K roads are clean $(0.688)$ was ranked low, thus there is the need to intensify and strictly focus on these respective factors.

Facilitation (Suvidha): The Facilitation (Suvidha) factor grouping variable (0.699) was ranked the fifth significantly influential factor that accounts for tourism development by the respondents. Individually, quality 
food is available at most of the tourist destinations in $\mathrm{J} \& \mathrm{~K}(0.717)$ and accommodation is easily available at most of the tourist destinations in $J \& K(0.715)$ was ranked the highest variable under Facilitation (Suvidha) factor indicating more important to tourism development than the other variables. On the other hand, Transporters are available round the clock in $\mathrm{J} \& \mathrm{~K}$ (0.665) was ranked low, thus there is the need to intensify and strictly focus on these respective factors.

Infrastructure (Samrachna): The Infrastructure (Samrachna) factor grouping variable (0.697) was ranked the sixth significantly influential factor that accounts for tourism development by the respondents. Individually, J\&K has a large number of food outlets which provide quality service $(0.758)$ and $J \& K$ fulfills accommodation needs of all classes of tourists $(0.725)$ was ranked the highest variable under infrastructure (Samrachna) factor indicating more important to tourism development than the other variables. On the other hand, J\&K has good road network (0.667) and $\mathrm{J} \& \mathrm{~K}$ has excellent communication services(internet \& telecom) available round the clock (0.638) was ranked low, thus there is the need to intensify and strictly focus on these respective factors.

Information (Soochna): The Information (Soochna) factor grouping variable (0.688) was ranked the seventh last significantly influential factor that accounts for tourism development by the respondents. Individually, Required information about safety measures at tourist destinations is provided by concerning authorities (0.696) and required information about the transportation costs to different destination is openly available (0.692) was ranked the highest variable under Information (Soochna) factor indicating more important to tourism development than the other variables. On the other hand, required information about the accommodation at different places in $J \& \mathrm{~K}$ is easily available (0.677) was ranked low, thus there is the need to intensify and strictly focus on these respective factors.

\section{Conclusion}

The paper empirically establishes the fact that tourism development is predominantly the result (in sequence) of Safety (Suraksha), Cooperation (Sahyog) factor, Welcome (Swagat), Cleanliness (Safai), Facilitation (Suvidha), Infrastructure (Samrachna) and Information (Soochna) factors. Nonetheless, the critical items that influence tourism development under their respective factor groups are recommend others to visit $\mathrm{J} \& \mathrm{~K}$ because it is safe, feel safe and secure in $\mathrm{J} \& \mathrm{~K}$, people in $\mathrm{J} \& \mathrm{~K}$ are very helpful, transporters properly assist in reaching different destinations of $\mathrm{J} \& \mathrm{~K}$, people in $\mathrm{J} \& \mathrm{~K}$ are friendly, shopkeepers are lively \& interactive, most of the hotels visited are clean, most of the restaurants visited have clean space, quality food is available at most of the tourist destinations in $J \& K$, accommodation is easily available at most of the tourist destinations in $\mathrm{J} \& \mathrm{~K}, \mathrm{~J} \& \mathrm{~K}$ has a large number of food outlets which provide quality service, J\&K fulfills accommodation needs of all classes of tourists, Required information about safety measures at tourist destinations is provided by concerning authorities and Required information about the transportation costs to different destination is openly available. The findings provide an understanding into the factors that contribute to tourism development.

There is an hour of need for the sustenance of tourism development in J\&K. It becomes clear from the study that the proper approach must be followed by the government led, private sector driven and community welfare oriented like the state government, municipal committees, hoteliers, travel and tourist agents towards providing the adequate attention to the tourists and the development of practically feasible tourism policies.

The limitation of the study includes feedback from the tourists which was based on their memory recall and experience pointing towards memory and experience bias. Though, cross checking at proper intervals has led to reduction in bias. Further, availability of foreign tourists to give feedback was cumbersome due to differences in language and in hurry but the researcher still managed to tackle this issue with care.

\section{References}

1. Ahmed, Z. U., \& Krohn, F. B. Reversing the United States declining competitiveness in the marketing of international tourism: a perspective on future policy. Journal of Travel Research. 1990;29(2):23-29.

2. Ali, S. and Fazili, A.I. (2017). Relative Importance of Factors Influencing Factory Sickness: A Case Study of Government Silk Weaving Factory Rajbagh. Global Journal of Commerce \& Management Perspective. 2017;6(5):1-6.

3. Badu, E., Owusu-Manu, D., Edwards, J.D., Adesi, M. and Lichtenstein, S. Rural Infrastructure Development in the Volta Region of Ghana: Barriers and Interventions, Journal of Financial Management of Property and Construction, 2013;18:142-159.

4. Fazili, A. I., \& Ashraf, S. H. (2006). Tourism in India Planning \& Development. Sarup \& Sons.

5. Gantzer, H. \& C. Gantzer (1983). Managing Tourists and Politicians in India. Tourism Management, June 1983. pp. 118-125

6. Gunce, E. Tourism and local attitudes in Girne, Northern Cyprus. Cities, 2003;20(3):181-195.

7. Hair, J. F. (2010). Multivariate data analysis. Pearson College Division.

8. Hair, J. F., Anderson, R. E., Tatham, R. L., \& Black, W. C. (1998). Multivariate data analysis, 5th. NY: Prentice Hall International.

9. Hawkins, D.E., (1982). Social and Economic Impact of Tourism on Asian Pacific Region. Tokyo: Asian Productivity Organization.

10. India Tourism Statistics (2015). Ministry of Tourism, Market Research Division New Delhi: GOI.

11. Johnson, J. W. A heuristic method for estimating the relative weight of predictor variables in multiple regression, Multivariate behavioral research, 2000;35(1):1-19. 
12. Johnson, J.W. and LeBreton, J.M. History and Use of Relative Importance Indices in Organizational Research, Organizational Research Methods, 2004;7:238-257.

13. Khan, O.F. and Kirmani, M.S. Seven Key Factors of 2002 National Tourism Policy- An Empirical Study of Kashmir, International Journal of Economics, Commerce and Research. 2018;8(3):1-8.

14. Lee, C. K., Kang, S. K., Long, P., \& Reisinger, Y. Residents' perceptions of casino impacts: A comparative study. Tourism Management. 2010;31(2):189-201.

15. National Tourism Policy (2002). Ministry of Tourism, New Delhi: GOI.

16. Prentice, R. Community driven tourism planning and residents' preferences. Tourism Management, 1993;14:218-227.
17. Raghuraman, K. Troubled Passage to India. Tourism Management. 1998;19(6);533.

18. Singh, S. (2001) Indian Tourism: Policy, Performance and Pitfalls. In: Harrison, D. (ed.) Tourism and the Less Developed World, Issues and Case Studies. Oxon: Cabi.

19. Smith, M. D., \& Krannich, R. S. Tourism dependence and resident attitudes. Annals of Tourism Research. 1998;25(4):783-802.

20. Tonidandel, S., LeBreton, J. M., \& Johnson, J. W. Determining the statistical significance of relative weights, Psychological methods. 2009;14(4):387.

21. World Tourism Organization, Report WTO (1995). 